9-18-2015

\title{
Future Orientation as a Protective Factor for African American Adolescents Exposed to Community Violence
}

\author{
Suzanna So \\ Loyola University Chicago \\ Noni K. Gaylord-Harden \\ Loyola University Chicago, ngaylor@luc.edu \\ Dexter R. Voisin \\ University of Chicago \\ Darrick Scott
}

Follow this and additional works at: https://ecommons.luc.edu/psychology_facpubs

Part of the Community Psychology Commons, and the Developmental Psychology Commons Author Manuscript

This is a pre-publication author manuscript of the final, published article.

\section{Recommended Citation}

So, Suzanna; Gaylord-Harden, Noni K.; Voisin, Dexter R.; and Scott, Darrick. Future Orientation as a Protective Factor for African American Adolescents Exposed to Community Violence. Youth \& Society, 50, 6: 34, 2015. Retrieved from Loyola eCommons, Psychology: Faculty Publications and Other Works, http://dx.doi.org/10.1177/0044118X15605108

This Article is brought to you for free and open access by the Faculty Publications and Other Works by Department at Loyola eCommons. It has been accepted for inclusion in Psychology: Faculty Publications and Other Works by an authorized administrator of Loyola eCommons. For more information, please contact ecommons@luc.edu. cc) (i) $\Theta$

This work is licensed under a Creative Commons Attribution-Noncommercial-No Derivative Works 3.0 License. (c) SAGE Publications 2018 


\section{Running Head: FUTURE ORIENTATION}

Future Orientation as a Protective Factor for African American Adolescents Exposed to Community Violence

Suzanna So ${ }^{1}$, Noni K. Gaylord-Harden ${ }^{1}$, Dexter R. Voisin ${ }^{2}, \&$ Darrick Scott $^{3}$

${ }^{1}$ Loyola University Chicago, Chicago, IL, United States.

${ }^{2}$ University of Chicago, Chicago, IL, United States.

${ }^{3}$ University of Massachusetts, Boston, MA, United States.

Accepted: August 18, 2015 


\begin{abstract}
For African American youth disproportionately exposed to community violence and the associated risk of externalizing behaviors, developmental assets that reduce the risk for externalizing behaviors and enhance adaptive coping should be explored. In a sample of 578 African American adolescents (mean age $=15.85 ; S D=1.42)$, the current study explored whether future orientation or gender buffered the impact of community violence exposure on externalizing behaviors. The current study also examined the interaction between future orientation, gender, and violence-specific coping strategies to determine their association with externalizing behaviors. Future orientation moderated the relationship between violence exposure and delinquent, but not aggressive, behaviors. Future orientation interacted differently with coping for males and females to predict externalizing behaviors. Research and clinical implications are discussed.
\end{abstract}

KEY WORDS: future orientation, coping, community violence exposure, aggression, delinquency 


\section{Future Orientation as a Protective Factor for African American Adolescents Exposed to Community Violence}

Community violence exposure is defined as frequent and continuous exposure to the use of guns, knives, drugs, and random violence (Osofsky, 1995), and two main forms of violence exposure are identified by research. Victimization is conceptualized as being the object of intentional acts initiated by another person to cause harm, such as being threatened, robbed, physically attacked, shot or stabbed; whereas witnessing is conceptualized as hearing or seeing an event that involves loss of property, threat of physical injury, actual injury, or death (Fowler, Tompsett, Braciszewski, Jacques-Tiura, \& Baltes, 2009). As a result of societal inequalities, a disproportionate number of adolescents living in low-income, urban neighborhoods are African American. Previous studies find that between $45 \%$ and $96 \%$ of African American youth from urban communities have witnessed violence in their community, ranging from assault to murder (Gaylord-Harden, Cunningham \& Zelencik, 2011; Self-Brown et al., 2006) and estimates ranging from 16\% to 37\% of African American youth from urban communities have reported violent victimization (Farrell \& Bruce, 1997; Spano \& Bolland, 2013). For African American adolescents in urban communities, exposure to community violence has a significant influence on daily life and impinges negatively upon optimal development (Kuther \& Wallace, 2003).

\section{The Impact of Exposure to Violence on Aggressive and Delinquent Behavior}

Although overall community violence has declined in the United States since the early 1990s, violence is still the leading cause of mortality for African American male youth (Thomas, Woodburn, Thompson, \& Leff, 2011). Homicide rates reflect one aspect of exposure to community violence and according to the Centers for Disease Control and Prevention (CDC), trend analyses between 1999 and 2007 revealed that age-adjusted homicide rates were consistently highest among African Americans. Further, during each year within that time frame, the homicide rate was approximately 2 
to 5 times higher among African Americans than among other ethnic groups (Logan, Smith, \& Stevens, 2011).

These trends are not surprising, given that community violence exposure is consistently associated with deviant and externalizing behavior among children, adolescents, and young adults in both cross-sectional and longitudinal studies (Fitzpatrick, 1997; Fowler et al., 2009; Gorman-Smith \& Tolan, 1998). In fact, community violence, while linked to numerous psychological and behavioral outcomes, has shown the most consistent and strongest associations to aggressive behavior (McDonald \& Richmond, 2008) and predicts delinquent behaviors over time even while controlling for prior levels of delinquency (Pearce, Jones, Schwab-Stone, \& Ruchkin, 2003). While aggressive and delinquent behaviors are often used as interchangeable constructs within the literature, these two types of externalizing behaviors are distinct: aggressive behaviors include bullying, fighting, temper tantrums, and cruelty, whereas delinquent behaviors include lying, stealing, truancy, and vandalism (Barnow, Lucht, \& Freyberger, 2005; Fergusson, Horwood, \& Lynsky, 1994). Few research studies have distinguished between these two sets of behaviors, but different risk factors are associated with the two (Cheong \& Raudenbush, 2000; Barnow, Lucht, \& Freyberger, 2005). On the whole, community violence exposure may lead to aggressive and delinquent behavior through normalization of violence, poor coping skills, decreased self-efficacy, and hopelessness (Dempsey, 2002; McMahon, Felix, Halpert, \& Petropoulos, 2009). Violence exposure may result in cognitive schemas that depict the world as hostile, and consequently, exposed youth may endorse normative beliefs that aggression is more acceptable (Guerra, Huesmann, \& Spindler, 2003). This promotes a cycle of community violence exposure and violence perpetuation among youth, which then places youth at a higher risk for other psychosocial problems, such as posttraumatic stress and anxiety symptoms (Scarpa, 2003). 
However, it should be noted that not all African American adolescents exposed to community violence show elevated rates of externalizing behavior (Copeland-Linder, Lambert, \& Ialongo, 2010). For example, in a profile analysis of fifth grade students exposed to community violence, results indicated that there were no significant differences in aggressive behaviors one year later across three classes of individuals: the vulnerable group, the moderate risk and medium protection group, and the moderate risk and high protection group (Copeland-Linder, Lambert, \& Ialongo, 2010). In other words, the group of participants who reported the highest rates of exposure to community violence did not exhibit the most aggression; thus, the relationship between exposure to community violence and aggression may be more conditional than previously thought. Simply being exposed to community violence is not indicative of whether youth will engage in aggressive or delinquent behaviors. Given the complexity of the relationship between community violence exposure and psychosocial outcomes, additional research is warranted to understand how community violence exposure leads to aggressive or delinquent behaviors in adolescents and to identify malleable protective factors that interrupt this risk cycle. Using theories of learned helplessness (Seligman, 1972) and learned hopelessness (Abramson, Metalsky, and Alloy, 1989) as guides, the current study examined coping efforts and future orientation as protective factors that may buffer the deleterious effects of community violence exposure.

\section{Coping Strategies used with Stressors and Exposure to Community Violence}

In particular, given the number of stressors that youth in urban communities encounter each day, they often develop various methods of coping to manage their environment. Interestingly, different studies have come to varied conclusions about how coping strategies impact aggressive and delinquent behaviors among youth who are exposed to community violence. The majority of research on African American youth exposed to high levels of stress utilizes the approach (active) coping versus avoidant coping model to examine adaptiveness of coping strategies (Dempsey, 
Overstreet, \& Moely, 2000; Edlynn, Gaylord-Harden, Richards, \& Miller, 2008; Grant et al., 2000). In general, active coping is consistently related to more adaptive outcomes, while avoidant coping is consistently related to more maladaptive outcomes (Compas et al., 2001; Clarke, 2006). However the patterns for coping with community violence have been much less consistent when using these general coping strategies. For example, in some studies, avoidant coping is protective and associated with lower levels of behavioral arousal or delinquency for youth exposed to community violence (Dempsey, Overstreet, \& Moely, 2000; Rosario, Salzinger, Feldman, Ng-Mak, 2003). Yet, other researchers found that avoidant coping is a vulnerability factor that leads to more aggression in response to violence (Rosario et al., 2003; Scarpa \& Haden, 2006). Further, other studies have not shown a significant relationship between active coping and aggressive behavior for youth exposed to violence (Dempsey, Oversteet, \& Moely, 2000; Scarpa \& Haden, 2006).

Given the inconsistencies in prior research, it has been suggested that the uncontrollable and chronic nature of community violence may result in unique patterns of coping (Edlynn et al., 2008; Garbarino, Kostelny, \& Dubrow, 1991) that are not captured on existing measures of general coping (e.g., avoidant and active coping). As a result, there may be a need to examine the role of coping strategies that are specific to community violence exposure. However, few studies have examined how African American youth cope specifically with exposure to community violence. One exception includes a recent qualitative study with African American adolescents that identified four forms of coping that are specific to community violence (Voisin, Bird, Hardestry, \& Shiu, 2011). Specifically, getting through coping is characterized by an acceptance of community conditions or an attempt to engage in positive behaviors to get out of the community. Getting along coping included aligning or associating with individuals who could offer protection. Getting away coping included avoidance coping strategies. Getting back coping included confrontational coping strategies that involved learning to fight or defend oneself. Despite the possible utility of these coping strategies, there is no 
existing quantitative research that examines the adaptiveness of these strategies for violence exposure, and it remains unclear how these coping strategies impact externalizing behaviors for African American youth exposed to violence (Voisin et al., 2011). Thus, the current study adds significantly to the literature by examining the adaptiveness of these violence-specific coping strategies.

Theories of learned helplessness (Seligman, 1972) highlight the relationship of uncontrollable stress to subsequent coping efforts, and propose that repeated exposure to uncontrollable stressors, such as community violence, results in fewer efforts to cope and more behavioral problems. However, youth who cope effectively with community violence can develop strategies to better accept developmental challenges that will allow them to deal with these challenges more positively in the long term (Garbarino, 2001). Although the literature on the adaptiveness of coping strategies among adolescents exposed to community violence is inconsistent, this is an important area of research due to the risks associated with learned helplessness behavior. As such, it is necessary to identify positive developmental assets that are particularly protective for youth exposed to high levels of violence and that assist in both reducing the risk of aggressive and delinquent behavior in the face of violence exposure and in enhancing the coping efforts of youth exposed to violence.

\section{Future Orientation among Urban Youth and Adolescents}

Although a number of positive developmental assets have been identified in the literature, future orientation may be particularly relevant for youth in communities with high crime and violence. Future orientation is a multi-dimensional cognitive-motivational construct that provides the foundation for setting one's goals and plans for the future (Stoddard, Zimmerman, \& Bauermeister, 2011) and for developing expectations and personal meaning for future events (McCabe \& Barnett, 2000; Nurmi, 1991). Indeed, the literature on possible selves, which are representations of self in the future, asserts that the way that youth think of themselves in the future 
can guide and regulate current behavior (Oyserman, Bybee, Terry \& Hart-Johnson, 2004). In other words, thinking of oneself in a desirable future state motivates the youth to pursue that end state by engaging in behaviors that facilitate the end state or avoiding behaviors that reduce the likelihood of the end state. Thus, future orientation could greatly impact how adaptively youth decide to cope with community violence and whether they engage in violent behavior. However, little is known about the relationship between future orientation and aggression or delinquent behaviors specifically for youth exposed to community violence.

Extensions of the learned helplessness theory propose that repeated exposure to an uncontrollable stressor also leads to learned hopelessness (Abramson, Metalsky \& Alloy, 1989; Rose \& Abramson, 1992), in which individuals begin to view a stressor as stable and global. Given the uncontrollable nature of community violence exposure, adolescents who grow up in violent environments may develop more hopelessness and be less able to perceive a future for themselves, and as a result, they may be less concerned with the long-term consequences of risky or aggressive behavior (Stoddard, Zimmerman, \& Bauermeister, 2011). Indeed, hopelessness can predict youth engagement in high-risk and violent behaviors (DuRant, Cadenhead, Pendergrast, Slavens, \& Linder, 1994). However, youth who are raised in high risk environments, but who sustain hope and positive expectations for the future, are less likely to experience psychosocial problems than those who do not engage in future planning (McCabe \& Barnett, 2000; Wyman, Cowen, Work, \& Kerley, 1993). Research with African American youth exposed to violence demonstrates that higher levels of future orientation are associated with few violent and externalizing behaviors (Cedeno, Elias, Kelly, \& Chu, 2010; Stoddard et al., 2011).

During adolescence, understanding how current behaviors affect future goals greatly impacts the ability to plan ahead and to realize the consequences of behavior. The process of future orientation could be essential to successfully navigate this developmental stage and could be a 
particularly important protective factor for African American adolescents living in risky

environments (McCabe \& Barnett, 2000). Interestingly, there have been a limited number of studies examining how future orientation may interact with exposure to community violence or coping strategies to predict aggressive or delinquent behaviors among urban African American youth, and additional research is warranted to determine the nature of these relationships.

\section{The Current Study and Hypotheses}

Given that community violence is often an uncontrollable stressor (Grant et al., 2000), and thus, may lead to hopelessness and restricted views of one's future, youth with high levels of violence exposure may be more likely to engage in risky or aggressive behaviors (Stoddard, Zimmerman, \& Bauermeister, 2011). However, future orientation may act to reduce the likelihood of externalizing behaviors by helping youth to focus on long-term consequences of such behavior and/or focus on their desired outcomes for their future. Not only is future orientation particularly relevant for the subset of African American youth growing up in communities with high levels of violence, future orientation increases during adolescence (Steinberg et al., 2009), making this developmental period an ideal time to examine the influence of future orientation.

Given the complexities of the relationship between community violence and externalizing behaviors, it is important to determine whether future orientation interacts with exposure to community violence and with different strategies youth use to cope with violence exposure. Thus, the primary objective of the current study was to determine whether future orientation was protective in the relationship between exposure to community violence and both aggressive and delinquent behaviors for African American adolescents. Based on prior literature, we hypothesized that higher levels of community violence would be associated with lower levels of both aggressive and delinquent behaviors at high levels of future orientation, but there would not be a significant relationship at low levels of future orientation. Because exposure to community violence could lead 
to aggressive behaviors through poor coping, the secondary objective of the current study was to examine the association between future orientation and coping strategies specific to community violence in the prediction of both aggressive and delinquent behaviors. The paucity of research on future orientation and coping limited the ability to make specific predictions, therefore, the present study sought to answer the following questions: Does future orientation interact with strategies to cope with violence exposure in the prediction of aggressive and delinquent behaviors?

\section{Methods}

\section{Participants}

Data from the current study were derived from a larger study examining community violence exposure and HIV risk via psychological distress, school achievement, and negative peer group associations in African American adolescents in a large metropolitan area. The original project collected data between December 2013 and June 2014. There were a total of 638 high school students who participated in the larger study, and 572 of these participants had complete data on the variables of interest in in the current study. Among the 572 participants (Mean age $=15.85 ; \mathrm{SD}=$ $1.42 ; 53.8 \%$ female) who were included in the current study, $32.9 \%$ were freshmen, $27.1 \%$ were sophomores, $19.0 \%$ were juniors, and $21.0 \%$ were seniors. Participants who were included in the current study were not significantly different from excluded participants on gender, age, or grade.

\section{Procedure}

A total of nine recruitment sites were targeted ( 3 high schools, 1 youth church group, 2 community youth programs, and 4 public venues frequented by youth such as parks, fast food outlets and movie theaters). The majority of participants were recruited in school and community programs (88\%), and the rest in churches $(9 \%)$ and public venues (4\%). Participants were recruited from urban, low-income African American communities in a large metropolitan area, where the average yearly median incomes ranged from $\$ 24,049$ to $\$ 35,946$, with the city average being $\$ 43,628$. 
Over the past 12 months, the violent crime index from these communities ranged from 190 to 735, with the city mean being 285.64 (Chicago Police Department, 2015). Communities were predominantly classified as racially and socioeconomically homogenous. The percentage of singlemother households in these areas ranged from $28.9 \%$ to $32.3 \%$, with the city average being $13.9 \%$.

The study was approved by a university institutional review board. Permission was obtained from principals and leaders of church groups and youth programs to recruit for the study. Flyers describing the study were posted at each of the locations, and the study was introduced to all potential participants by research assistants. Youth recruited from schools, community programs, and churches were provided with a detailed letter describing the study along with parental consent forms. Youth who returned signed consent forms were assented and enrolled in the study. Youth recruited in public venues were only asked to participate if a parent was present to offer consent. Active parental consent and youth assent were obtained for all participants in the study.

Trained research assistants supervised all participants completing the survey to minimize interruptions and to maintain an environment of confidentially. Those recruited from schools, community programs, and churches were administrated the survey in those respective locations. The few individuals who were recruited in public venues (e.g., parks and fast food venues) were administered the questionnaires in quiet spaces at or near those venues.

\section{Measures}

Demographics. Information was collected on a variety of demographic variables, including: age, gender, race, and grade level.

Exposure to Community Violence. Lifetime exposure to community violence was assessed by utilizing a subset of items derived from the Exposure to Violence Probe (Stein, Walker, Hazen, \& Forde, 1997; Voisin, 2002). In particular, 7 items measured the frequency of witnessing or personally experiencing violent acts over the lifetime: Close relative or friend died violently; Close relative or 
friend seriously injured; Close relative or friend robbed or attacked; Seen someone being beaten; Victim of violence; Seen dead body; and Witnessed gun related incident. Items were rated on a seven-point scale ("0 times" to "more than 6 times"), and a composite score for exposure to community violence was calculated by summing up the 7 items. Consistent with other studies (Voisin, Neilands, \& Hunnicutt, 2011), $\alpha=$.73), the composite score included both witnessing and victimization. Composite scores ranged from 0 to 42, and Cronbach's alpha for the current sample was acceptable $(\alpha=.87)$.

Future Orientation. Future orientation was assessed with a modified version of a scale (Whitaker, Miller, \& Clark, 2000) with items derived from Coopersmith's self-esteem scale (Coopersmith, 1967). Items from the modified scale have been adapted and used in prior research (Robbins \& Byran, 2004, $\alpha=.73$ ). In the current study, 10 items inquired about perceptions of perceived control (e.g. I have little control over the things that happen to me), positive future outlook (e.g. What happens to my future mostly depends on me), and hopelessness (e.g. Sometimes I feel there is nothing to look forward to in the future ) within the last 6 months on a three-point scale ( 1 = "not true," 2 = "somewhat or sometimes true," 3 = "very true or often true"). A future orientation score was calculated by using the mean of the 10 items. Mean scores ranged from 1.40 and 3.00, and Cronbach's alpha for the current sample was acceptable $(\alpha=.64)$.

Aggressive Behaviors. Aggressive behaviors were assessed with the Illinois Bully Scale (Espelage \& Holt, 2001), which contains 18 items that inquire about the frequency of engaging and being a victim of aggressive behaviors in the last 30 days (e.g., I upset other students for the fun of it) on a five-point scale (from never to 7 or more times). A composite aggressive behaviors score was calculated by summing the responses for the 14 items on the bullying and fighting subscales. Composite scores ranged from 0 to 56, and Cronbach's alpha for the current sample was acceptable 
$(\alpha=.90)$. Due to positive skewness of the composite scores, logarithmic transformations were used in analyses.

Delinquent Behaviors. Delinquent behaviors were measured with a revised version of an instrument assessing delinquency in prior study (Chen, Voisin, \& Jacobson, 2013). For the current study, 10 items inquired about the frequency of illegal, norm-violating, and aggressive behaviors in the last 12 months (e.g. Used a knife or gun or some other thing (such as a bat, pipe, razor, taser, mace) to get something from a person). Responses were rated on a six-point scale from 0 times to 12 or more times, and a composite delinquent behaviors score was calculated by summing the responses for all 10 items. Composite scores ranged from 0 to 41, and Cronbach's alpha for the current dataset was acceptable $(\alpha=.90)$. Due to positive skewness of the composite scores, logarithmic transformations were used in analyses.

Coping. The Coping with Community Violence Scale (CWCV; Gaylord-Harden \& Voisin, 2012) was developed as a result of the findings in Voisin et al.'s (2011) qualitative study, which explored specific approaches to coping with exposure to community violence. The CWCV contains 29 items that inquire how often participants behave or feel a certain way about problems related to violence in their community on a four-point scale $(0=$ "never" to $3=$ "very often"). These items are combined to form 4 subscales: getting through (e.g. I try to work hard in school, so that I can get out of my community), getting along (e.g. I try to get to know as many people as possible in my community), getting away (e.g. I try to avoid places where violence may happen), and getting back (e.g. I fight back if someone attacks me). Victimization has been found to have a positive correlation with getting through, while witnessing community violence has been found to have a positive correlation with getting through, getting along, and getting back. In addition, getting along has shown positive associations with PTSD, depression, and aggression, while getting away has shown positive associations with aggression (Gaylord-Harden, Scott, \& Voisin, 2013). Mean scores for each 
subscale ranged from 1 to 4 . Besides getting back $(\alpha=.41)$, each subscale had acceptable Cronbach's alphas: getting through $(\alpha=.75)$, getting along $(\alpha=.76)$, and getting away $(\alpha=.67)$. Due to a low alpha, getting back was dropped from the analyses for the current study.

\section{Results}

Means, standard deviations, and correlations for all study variables are presented in Table 1. Compared to females, preliminary t-tests revealed that males were exposed to significantly greater levels of community violence, $t(509.77)=3.79, p<.001$, males engaged in significantly more delinquent behaviors, $t(428.14)=4.20, p<.001$. T-tests also indicated that males and females did not significantly differ on aggressive behaviors, future orientation, or any of the coping subscales.

To address both objectives of the current study, moderation analyses were conducted with hierarchical linear regression. Due to the gender differences for exposure to community violence (ECV) and delinquent behaviors in the preliminary analyses, gender was added to the analyses as a

third interaction term. Two models were tested, one for aggressive behavior as the outcome and one for delinquent behavior as the outcome. In each of the regression analyses, grade level was entered in Step 1 of each model to account for its effects. Centered variables for ECV, future orientation, gender, and the coping subscales were simultaneously entered in Step 2 of each model. Two-way interaction terms were created for ECV, future orientation, gender, and each of the coping subscales. These twelve two-way interaction terms were simultaneously added into Step 3 of the models. Finally, three-way interaction terms were created for ECV, future orientation, and gender, as well as for each of the coping subscales, future orientation, and gender. These four three-way interaction terms were simultaneously entered into Step 4 of the models.

To address the first objective, the examination of future orientation as a moderator of the relationship between community violence exposure and outcomes, the three-way interaction term for ECV, future orientation, and gender, as well as the two-way interaction terms for ECV and 
future orientation and ECV and gender were examined for aggressive behaviors. As shown in Table 2, future orientation and gender did not significantly moderate the relationship between ECV and aggressive behaviors. However, there was a significant main effect of ECV in predicting aggressive behaviors, such that greater levels of exposure were associated with more aggressive behaviors.

Results for delinquent behavior did not reveal a significant three-way interaction among ECV, future orientation, and gender. However, there was a significant interaction between ECV and future orientation and between ECV and gender in the prediction of delinquent behaviors (Table 3). Simple slope analyses revealed that at both high and low levels of future orientation, higher levels of exposure to violence significantly predicted higher levels of delinquent behaviors. This effect appeared to be even more substantial at low levels of future orientation, $\beta=.45, p<.001$, compared to high levels of future orientation, $\beta=.29, p<.001$ (Figure 1). Another set of simple slope analyses revealed that for both males and females, higher levels of exposure to violence significantly predicted higher levels of delinquent behaviors. This effect appeared to be even more substantial for males, $\beta=.44, p<.001$, than females, $\beta=.32, p<.001$.

To address the second objective, the examination of future orientation as a moderator of the relationship between coping and outcomes, the three-way interaction terms for future orientation, gender, and the three coping subscales, as well as the two-way interaction terms were examined for aggressive behaviors. There was a significant three-way interaction for getting away coping, future orientation, and gender (Table 2). Follow-up regression analyses revealed that the interaction between getting away coping and future orientation was significant for males, $\beta=-.25, p<.001$, but not for females, $\beta=.03, p=.60$. More specifically, simple slope analyses revealed that at high levels of future orientation, higher levels of getting away coping were associated with significantly fewer aggressive behaviors, $\beta=-.26, p=.006$. At low levels of future orientation, higher levels of getting away coping were associated with significantly higher levels of aggressive behaviors, $\beta=.25, p=.003$. 
Results also indicated that there was a significant interaction between getting through coping and getting along coping in the prediction of aggressive behaviors (Table 2). Simple slope analyses revealed that at low levels of getting along coping, higher levels of getting through coping were associated with significantly more aggressive behaviors, $\beta=.18, p=.004$. This effect was not significant at high levels of getting along coping, $\beta=-.02, p=.79$.

In the prediction of delinquent behaviors, there was a significant three-way interaction for getting away coping, future orientation, and gender (Table 3). Follow-up regression analyses revealed that the interaction between getting away coping and future orientation was only significant for males, $\beta=-.18, p=.003$, but not for females, $\beta=.01, p=.85$. More specifically, simple slope analyses revealed that at high levels of future orientation, higher levels of getting away coping were associated with significantly fewer delinquent behaviors among males, $\beta=-.23, p=.01$. However, there were no significant effects at low levels of future orientation, $\beta=.13, p=.09$. Furthermore, gender moderated the relationship between getting through coping and delinquent behaviors (Table

3). Simple slope analyses revealed a negative association between getting through coping and delinquent behaviors for males, $\beta=-.04, p=.50$, and a positive association between getting through coping and delinquent behaviors for females, $\beta=.04, p=.43$. However, neither of these effects was significant.

\section{Discussion}

The primary objective of the current study was to determine whether future orientation was protective in the relationship between exposure to community violence exposure and both aggressive and delinquent behaviors. In line with previous literature, higher levels of exposure to community violence were associated with greater levels of both aggressive and delinquent behaviors, while greater levels of future orientation were associated with lower levels of both aggressive and delinquent behaviors. The moderation hypothesis that higher levels of future orientation would be 
associated with lower levels of both aggressive and delinquent behaviors at high levels of community violence was partially supported. Future orientation interacted with exposure to community violence in predicting delinquent behaviors, but not in the prediction of aggressive behaviors.

While there was not a three-way interaction among exposure to violence, future orientation, and gender in the prediction of delinquent behaviors, there was a significant exposure to violence and future orientation interaction, as well as a significant exposure to violence and gender interaction. The significant interaction between violence exposure and future orientation represented a "protective but reactive" effect for future orientation in predicting delinquent behaviors, which indicates that an attribute generally confers advantages, but less so when stress levels are high than low (Luthar, Cicchetti, \& Becker, 2000). Specifically, future orientation tends to be associated with fewer delinquent behaviors, but less so at high levels of exposure to community violence. Of particular interest, males demonstrated higher levels of delinquent behaviors than females, and high exposure to community violence combined with a low level of future orientation predicted the highest levels of delinquent behaviors. This demonstrates the importance of future orientation at high levels of uncontrollable stress. It appears that when adolescents are exposed to high rates of community violence and they do not feel like they have control over their futures, they are more likely to engage in more delinquent behaviors. As noted above, youth may develop a diminished perception of risk due to the hopelessness associated with the stress of exposure to community violence (Schwab-Stone et al., 1995). Indeed, one study of adolescents in high-crime, low-income communities showed that those adolescents in the sample exposed to the highest levels of community violence believed that their own death would be violent (Hinton-Nelson, Roberts, \& Snyder, 1996). Conversely, youth exposed to high levels of violence may believe that engaging in delinquent behaviors may protect them or their families (Vigil, 2003), and consequently, that these 
behaviors give them more control over their lives and their futures. More research is needed to determine the cognitions that may be mediating these relationships.

It is unclear why future orientation moderated the relationship between exposure to community violence and delinquent behaviors, but not the relationship between exposure to community violence and aggressive behaviors. This finding is especially interesting given that the strength of the association between community violence and delinquency is similar to the association between community violence and aggression in the current study. While the measure examining aggressive behaviors included behaviors that were related to peer interactions (e.g. harassing other students, fought students I could easily beat), the measure examining delinquent behaviors included more serious crimes (set fire to someone else's property on purpose, hurt someone badly enough for them to need a doctor). The findings suggest that the interaction between exposure to community violence and future orientation varies based on the severity of the externalizing behaviors in question, with more severe behaviors influenced by future orientation.

In addition, it is possible that the aggressive behaviors assessed with the Illinois Bully Scale may reflect behaviors that are associated with more normative beliefs about aggression (Guerra, Huesmann, \& Spindler, 2003). As such, future orientation may not demonstrate as strong of an effect on normative beliefs and behaviors. Furthermore, prior research has found peer rejection to be more strongly related to aggressive behaviors and only moderately linked to delinquency; while, deviance in the peer-group was found to be more closely related to delinquency and only moderately with aggression (Barnow, Lucht, \& Freyberger, 2005). Indeed, existing research demonstrates that peers may be important socializing agents for future orientation (Murray, 1996). Thus, one's level of future orientation and peer deviant behaviors may have a greater effect on whether one engages in delinquent behaviors, but not aggressive behaviors. Future research should further examine the 
interaction among future orientation, peer beliefs and behaviors, as well as normative beliefs about aggression in the prediction of aggressive or delinquent behaviors.

The secondary objective of the current study was to examine whether future orientation was a protective factor in the relationship between coping strategies specific to community violence and both aggressive and delinquent behaviors. Although males and females did not significantly differ on levels of future orientation or coping, results regarding the interactions between future orientation and the coping subscales did differ by gender. Specifically, future orientation and gender significantly moderated the relationship between getting away coping and aggressive behaviors, as well as getting away coping and delinquent behaviors. Of note, for both aggressive and delinquent behaviors, the getting away coping and future orientation interaction was only significant for males. Thus, both gender and future orientation may be important factors to consider when addressing forms of coping among African American youth.

High levels of getting away coping predicted more aggressive and more delinquent behaviors at low levels of future orientation, but higher scores on getting away were associated with fewer aggressive and fewer delinquent behaviors at high levels of future orientation. Thus, there may be a protective effect of high levels of future orientation at high levels of getting away. The getting away coping subscale included items that inquired about whether participants tried to avoid situations where violence might occur. It is not surprising that participants who have greater levels of future orientation may try to avoid violent locations. As previously mentioned, some studies have shown that avoidant coping in response to community violence exposure was associated with lower levels of delinquency (Rosario et al., 2003), while other similar studies have shown that avoidant coping could lead to more aggression (Scarpa \& Haden, 2006). From the results of the current study, it appears that the inconsistency in findings may be partially explained by one's gender and differences in an individual's level of future orientation. In work with adjudicated youth, future orientation 
motivated youth towards future prosocial behavior (Clinkinbeard \& Zohra, 2011). Thus, youth with high future orientation who cope by avoiding violence may be doing so, not solely to protect themselves, but also to ensure that future goals of prosocial behavior are met. As noted in prior research, youth who visualize an improved future version of themselves may feel better and this visualization may incentivize prosocial behaviors that lead to their desired self (Clinkinbeard \& Zohra, 2011). Youth with low future orientation who cope by avoiding violence may be doing so to protect themselves, but are not avoiding violence within the context of a larger plan for behavior. Hence, from the results, it appears that certain types of coping may be more beneficial than other types in predicting fewer aggressive or delinquent behaviors, but the advantages and disadvantages of these coping strategies depends on levels of future orientation and varies by gender.

Although getting through coping significantly interacted with gender in the prediction of delinquent behaviors in the regression analyses, simple slope analyses indicated that there was not a significant association between getting through coping and delinquent behaviors for either males or females. It is possible that simply analyzing getting through coping at one standard deviation above and below the mean may not address the subtleties that underlie this type of coping for males and females. Future studies may benefit by further analyzing differences between males and females on getting through coping.

\section{Limitations}

The current study is not without limitations. First, each of the measures is self-report, and consequently, shared method variance cannot be completely ruled out. Moreover, we are focusing on a population of African American youth from specific communities, so these results may not be applicable for other ethnic groups or African American youth from more affluent communities. However, due to the high level of stressors that are present in the lives of African American youth affected by community violence in low-income, urban environments, this study is particularly 
relevant for violence prevention and intervention efforts that target those communities. Additionally, the current study was limited by the cross-sectional nature of the data.

While it may also be possible to conceptualize future orientation as a mediating variable rather than a moderating variable, the current study did not do so for a few reasons. First, the data are cross-sectional, and given the temporal nature of meditational models, it would not be appropriate to examine a meditational model with the current data. Secondly, as discussed by Holmbeck (1997), researchers who view constructs, like coping or future orientation, as a mediator propose that they are "response" variables and only exist in relation to the variables that preceded them. On the other hand, a moderator interacts with a predictor variable to have an impact on the level of a dependent variable. The current study sought to examine future orientation as a protective factor by examining its interaction effects with exposure to community violence and coping. As such, the current study did not seek to determine whether exposure to community violence leads to coping or future orientation, but whether differing levels of future orientation interact with exposure to community violence or coping to impact outcomes. Distinctions between moderator and mediator models are important because they may have different implications for applied work. The identification of moderating effects may have more clinical implications (i.e. identification of groups which are more resilient or vulnerable under certain conditions), and the identification of mediating effects may have more direct implications for the design of intervention programs (i.e., identification of why one variable has an effect on another variable) (Evans \& Lepore, 1997).

In light of these limitations, the current study has several strengths. The current study builds on prior research focused on protective factors for community violence exposure by examining an understudied, but contextually-relevant protective factor: future orientation. Given the sample size, gender was added as an additional interaction term. Further, the current study utilized a measure of coping that assessed strategies specific to community violence, providing preliminary evidence 
regarding how youth utilize coping strategies that develop from exposure to community violence in their neighborhoods. Moreover, rather than using an externalizing composite, the current study examined aggression and delinquency separately, as research supports the distinction of these two outcomes (Cheong \& Raudenbush, 2000; Barnow, Lucht, \& Freyberger, 2005).

\section{Implications}

Despite the limitations, the current study can inform further research about the complex relationship between exposure to community violence and aggressive or delinquent behaviors. Given the differences in our results based on the type of externalizing behavior, future research focused on identifying protective factors for violence exposure should differentiate between the two outcomes. Moreover, the influence of future orientation on coping may indicate that this is an area that needs to be further explored within the coping literature. Again, the findings across studies on coping with community violence are equivocal, yielding inconsistent results about which strategies may help these youth exposed to violence; however, findings of the current study suggest that variables that are related to motivating behavior may help to understand the adaptiveness of coping.

Given the number of psychosocial problems that may result from exposure to community violence, many programs have been created to either prevent or intervene against the effects of exposure on the development of aggressive or delinquent behaviors (Dahlberg, 1998; Tolan \& Guerra, 1994). The current results support the inclusion of the concept of future orientation in community violence intervention work with youth, especially among males. Because of the accumulation of stressors in the daily lives of youth and adolescents, they develop various methods of coping to manage their environments. However, it may be important for prevention and intervention programs not only to enhance coping skills, but to understand how future expectations and coping influence each other. These cognitive schemas could be a key variable in whether such programs are able to influence the daily lives of youth who witness or are victims of violence in their 
community. Interventions that work to counter low expectations and perceptions of control for the future among adolescents who are exposed to community violence may reduce delinquent behaviors in violence-exposed youth, but this work should also focus on teaching contextually-relevant strategies that make one’s goals for the future more attainable (Clinkinbeard \& Zohra, 2011). 


\section{References}

Abramson, L. Y., Metalsky, G. I., \& Alloy, L. B. (1989). Hopelessness depression: A theory-based subtype of depression. Psychological Review, 96, 358-372.

Adelabu, D. H. (2008). Future time perspective, hope, and ethnic identity among african american adolescents. Urban Education, 43(3), 347-360.

Barnow, S., Lucht, M., \& Freyberger, H. J. (2005). Correlates of aggressive and delinquent conduct problems in adolescence. Aggressive behavior, 31(1), 24-39.

Brown, W. T., \& Jones, J. M. (2004). The substance of things hoped for: A study of the future orientation, minority status perceptions, academic engagement, and academic performance of black high school students. Journal of Black Psychology, 30(2), 248-273.

Cedeno, L. A., Elias, M. J., Kelly, S., \& Chu, B. C. (2010). School violence, adjustment, and the influence of hope on low-income, African American youth. American Journal of Orthopsychiatry, 80(2), 213-226.

Chen, P., Voisin, D. R., \& Jacobson, K. C. (2013). Community violence exposure and adolescent delinquency: Examining a spectrum of promotive factors. Youth \& Society, $0044118 X 13475827$.

Cheong, Y. F., \& Raudenbush, S. W. (2000). Measurement and structural models for children's problem behaviors. Psychological Methods, 5(4), 477.

Clarke, A.T. (2006). Coping with interpersonal stress and psychosocial health among children and adolescents: A meta-analysis. Journal of Youth and Adolescence, 35(1), 11-24.

Chicago Police Department. (2008). Chicago Police Department CLEARMAP Crime Summary [Data file]. Retrieved from http://gis.chicagopolice.org/clearmap_crime_sums/startpage.htm\#

Clinkinbeard, S. S., \& Zohra, T. (2012). Expectations, fears, and strategies juvenile offender thoughts on a future outside of incarceration. Youth \& Society, 44(2), 236-257. 
Compas, B.E., Connor-Smith, J.K., Saltzman, H., Thomsen, A.H., \& Wadsworth, M.E. (2001).Coping with stress during childhood and adolescence: Problems, progress, potential in theory and research. Psychological Bulletin, 127(1), 87-127.

Coopersmith, S. (1967). The Antecedents of Self-Esteem, San Francisco, CA: W. H. Freeman.

Copeland-Linder, N., Lambert, S. F., \& Ialongo, N. H. (2010). Community violence, protective factors and adolescent mental health: A profile analysis. Journal of Clinical Child and Adolescent Psychology, 39, 176-186.

Dahlberg, L. L. (1998). Youth violence in the United States: Major trends, risk factors, and prevention approaches. American Journal of Preventive Medicine, 14(4), 259-272.

Dempsey, M. (2002). Negative coping as mediator in the relation between violence and outcomes: Inner-city African American youth. American Journal of Orthopsychiatry, 72(1), 102.

Dempsey, M., Overstreet, S., \& Moely, B. (2000). Approach and avoidance coping and PTSD symptoms in inner-city youth. Current Psychology: Developmental, Learning, Personality, Social, 19, $28-45$.

DuRant, R. H., Getts, A., Cadenhead, C., Emans, S. J., \& Woods, E. R. (1995). Exposure to violence and victimization and depression, hopelessness, and purpose in life among adolescents living in and around public housing. Developmental and Behavioral Pediatrics, 16, 233-237.

Edlynn, E. S., Gaylord-Harden, N. K., Richards, M. H., \& Miller, S. A. (2008). African American inner-city youth exposed to violence: Coping skills as a moderator for anxiety. American Journal of Orthopsychiatry, 78(2), 249.

Espelage, D. L. \& Holt, M. (2001). Bullying and victimization during early adolescence: Peer influences and psychosocial correlates. Journal of Emotional Abuse, 2, 123-142. 
Evans, G. W., \& Lepore, S. J. (1997). Moderating and mediating processes in environment-behavior research. In G.T. Moore \& R. W. Marans (Eds.), Advances in environment, behavior, and design, Vol. 4 (pp. 255-285). New York: Plenum.

Farrell, A. D., \& Bruce, S. E. (1997). Impact of exposure to community violence on violent behavior and emotional distress among urban adolescents. Journal of Clinical Child Psychology, 26(1), 2-14.

Fergusson, D. M., Horwood, L. J., \& Lynskey, M. T. (1994). Structure of DSM-R criteria for disruptive childhood behaviors: Confirmatory factor models. Journal of the American Academy of Child and Adolescent Psychiatry, 33, 1145-1155.

Fitzpatrick, K. M. (1997). Aggression and environmental risk among low-income African-American youth. Journal of Adolescent Health, 21(3), 172-178.

Fowler, P. J., Tompsett, C. J., Braciszewski, J. M., Jacques-Tiura, A. J., \& Baltes, B. B. (2009). Community violence: A meta-analysis on the effect of exposure and mental health outcomes of children and adolescents. Development and Psychopathology, 21(1), 227.

Garbarino, J. (2001). An ecological perspective on the effects of violence on children. Journal of Community Psychology, 29(3), 361-378.

Garbarino, J., Kostelny, K., \& Dubrow, N. (1991). What children can tell us about living in danger. American Psychologist, 46(4), 376.

Gaylord-Harden, N. K., Cunningham, J. A. \& Zelencik, B. (2011). Effects of exposure to community violence on internalizing symptoms: Does desensitization to violence occur in African American youth? Journal of Abnormal Child Psychology, 39, 711-719.

Gaylord-Harden, N. K., Scott, D. \& Voisin, D. (April 2013). African American male adolescents coping with exposure to community violence. In M. Wadsworth (Chair), When Avoidance Helps and Problem Solving Hurts: Understanding Children's Coping in the Context of Significant 
Environmental Risk. Paper presented at the 2013 Biennial Meeting of the Society for Research in Child Development. Seattle, WA.

Gaylord-Harden, N.K. \& Voisin, D. R. (2012). The coping with community violence scale.

Unpublished manuscript.

Gorman-Smith, D. \& Tolan, P. (1998). The role of exposure to community violence and developmental problems among inner-city youth. Development and Psychopathology, 10, 101-116.

Guerra, N.G., Huesmann, L.R., \& Spindler, A. (2003). Community violence exposure, social cognition, and aggression among urban elementary school children. Child Development, 74(5), 1561-1576.

Grant, K. E., O’Koon, J. H., Davis, T. H., Roache, N. A., Poindexter, L. M., Armstrong, M. L., ... \& McIntosh, J. M. (2000). Protective factors affecting low-income urban African American youth exposed to stress. The Journal of Early Adolescence, 20(4), 388-417.

Hinton-Nelson, M. D., Roberts, M. C., \& Snyder, C. R. (1996). Early adolescents exposed to violence: Hope and vulnerability to victimization. American Journal of Orthopsychiatry, 66, 346-353.

Holmbeck, G. N. (1997). Toward terminological, concept, and statistical clarity in the study of mediators and moderators : Examples from the child-clinical and pediatric psychology literatures. Journal of Consulting and Clinical Psychology, 65, 599-610.

Kuther, T. L., \& Wallace, S. A. (2003). Community violence and sociomoral development: An African American cultural perspective. American Journal of Orthopsychiatry, 73(2), 177.

Logan, J.E., Smith, S.G., \& Stevens, M.R. (2011). Homicides - United States, 1999-2007. Morbidity and Mortality Weekly Report, 60(1), 67-70.

Luthar, S. S., Cicchetti, D., \& Becker, B. (2000). The construct of resilience: A critical evaluation and guidelines for future work. Child Development, 71(3), 543-562. 
McCabe, K., \& Barnett, D. (2000). First comes work, then comes marriage: Future orientation among african american young adolescents. Family Relations, 49(1), 63-70.

McDonald, C. C., \& Richmond, T. R. (2008). The relationship between community violence exposure and mental health symptoms in urban adolescents. Journal of Psychiatric and Mental Health Nursing, 15(10), 833-849.

McMahon, S. D., Felix, E. D., Halpert, J. A., \& Petropoulos, L. A. (2009). Community violence exposure and aggression among urban adolescents: Testing a cognitive mediator model. Journal of Community Psychology, 37(7), 895-910.

Nurmi, J. E. (1991). How do adolescents see their future? A review of the development of future orientation and planning. Developmental Review, 11(1), 1-59.

Osofsky, J. D. (1995). The effects of exposure to violence on young children. American Psychologist, 50, $782-788$.

Oyserman, D., Bybee, D., Terry, K., \& Hart-Johnson, T. (2004). Possible selves as roadmaps. Journal of Research in Personality, 38(2), 130-149.

Pearce, M. J., Jones, S. M., Schwab-Stone, M. E., \& Ruchkin, V. (2003). The protective effects of religiousness and parent involvement on the development of conduct problems among youth exposed to violence. Child Development, 74(6), 1682-1696.

Robbins, R. N., \& Bryan, A. (2004). Relationships between future orientation, impulsive sensation seeking, and risk behavior among adjudicated adolescents. Journal of Adolescent Research, 19(4), 428-445.

Rosario, M., Salzinger, S., Feldman, R. S., \& Ng-Mak, D. S. (2003). Community violence exposure and delinquent behaviors among youth: The moderating role of coping. Journal of Community Psychology, 31(5), 489-512. 
Rose, D. T., \& Abramson, L. (1992). Developmental predictors of depressive cognitive style: research and theory. In D. Cicchetti \& S. Toth (Eds.), Rochester Symposium of Developmental Psychopathology, (Vol. IV, pp. 323-349). Rochester, NY: University of Rochester Press.

Scarpa, A. (2003). Community violence exposure in young adults. Trauma, Violence, \& Abuse, 4(3), 210-227.

Scarpa, A., \& Haden, S. C. (2006). Community violence victimization and aggressive behavior: The moderating effects of coping and social support. Aggressive Behavior, 32(5), 502-515.

Schwab-Stone, M. E., Ayers, T. S., Kasprow, W., Voyce, C., Barone, C., Shriver, T., \& Weissberg, R. P. (1995). No safe haven: A study of violence exposure in an urban community. Journal of the American Academy of Child \& Adolescent Psychiatry, 34(10), 1343-1352.

Self-Brown, S. R., LeBlanc, M., Kelley, M. L., Hanson, R., Laslie, K., \& Wingate, A. (2006). Effects of community violence exposure and parental mental health on the internalizing problems of urban adolescents. Violence and Victims, 21(2), 183-198.

Seligman, M. E. (1972). Learned helplessness. Annual Review of Medicine, 23, 407-412.

Spano, R., \& Bolland, J. (2013). Disentangling the effects of violent victimization, violent behavior, and gun carrying for minority inner-city youth living in extreme poverty. Crime \& Delinquency, 59(2), 191-213.

Stein, M. B., Walker, J. R., Hazen, A. L., \& Forde, D. R. (1997). Full and partial posttraumatic stress disorder: findings from a community survey. American Journal of Psychiatry, 154(8), 1114-1119.

Steinberg, L., Graham, S., O’Brien, L., Woolard, J., Cauffman, E., \& Banich, M. (2009). Age differences in future orientation and delay discounting. Child Development, 80(1), 28-44.

Stoddard, S. A., Zimmerman, M. A., \& Bauermeister, J. A. (2011). Thinking about the future as a way to succeed in the present: A longitudinal study of future orientation and violent 
behaviors among African American youth. American Journal of Community Psychology, 48(3-4), 238-246.

Thomas, D. E., Woodburn, E. M., Thompson, C. I., \& Leff, S. S. (2011). Contemporary interventions to prevent and reduce community violence among African American youth. In Handbook of African American Health (pp. 113-127). New York, NY: Springer.

Tolan, P. H., \& Guerra, N. G. (1994). What works in reducing adolescent violence: An empirical review of the field. Monograph prepared for the Center for the Study and Prevention of Youth Violence. Boulder: University of Colorado.

Vigil, J. D. (2003). Urban violence and street gangs. Annual Review of Anthropology, 225-242.

Voisin, D. R. (2002). Family ecology and HIV sexual risk behaviors among African American and Puerto Rican adolescent males. American Journal of Orthopsychiatry, 72(2), 294.

Voisin, D. R., Bird, J. D., Hardestry, M., \& Shiu, C. S. (2011). African American adolescents living and coping with community violence on chicago's southside. Journal of Interpersonal Violence, 26(12), 2483-2498.

Voisin, D. R., Neilands, T. B., \& Hunnicutt, S. (2011). Mechanisms linking violence exposure and school engagement among African American adolescents: Examining the roles of psychological problem behaviors and gender. American Journal of Orthopsychiatry, 81(1), 61-71.

Whitaker, D. J., Miller, K. S., \& Clark, L. F. (2000). Reconceptualizing adolescent sexual behavior: Beyond did they or didn't they? Family Planning Perspectives, 32, 111-117.

Wyman, P. A., Cowen, E. L., Work, W. C., \& Kerley, J. H. (1993). The role of children's future expectations in self-system functioning and adjustment to life stress: A prospective study of urban at-risk children. Development and Psychopathology, 5(04), 649-661. 
Table 1.

Means, standard deviations, and Pearson's correlations among the main study variables for the overall sample

\begin{tabular}{|c|c|c|c|c|c|c|c|c|c|}
\hline Variables & Mean & S.D. & 1 & 2 & 3 & 4 & 5 & 6 & 7 \\
\hline 1. $\mathrm{ECV}$ & 9.90 & 9.10 & & & & & & & \\
\hline 2. Future Orientation & 2.44 & 0.35 & $-0.13^{* *}$ & & & & & & \\
\hline 3. Aggressive Behaviors & 0.69 & 0.48 & $0.34^{* * *}$ & $-0.09^{*}$ & & & & & \\
\hline 4. Delinquent Behaviors & 0.30 & 0.40 & $0.39^{* * *}$ & $-0.27^{* * *}$ & $0.47^{* * *}$ & & & & \\
\hline 5. Getting Through & 2.41 & 0.60 & $0.15^{* * *}$ & 0.02 & $0.09^{*}$ & -0.01 & & & \\
\hline 6. Getting Along & 2.45 & 0.68 & $0.10^{*}$ & $0.17^{* * *}$ & 0.07 & -0.03 & $0.58^{* * *}$ & & \\
\hline 7. Getting Away & 2.15 & 0.59 & 0.02 & -0.04 & -0.02 & -0.06 & $0.58^{* * *}$ & $0.43^{* * *}$ & \\
\hline
\end{tabular}

Notes: Logarithmic-transformed terms are presented for aggressive and delinquent behaviors; ECV = exposure to community violence; ${ }^{* * *} p<.001,{ }^{* *} p<.01,{ }^{*} p<.05$ 
Table 2.

Final model examining future orientation (FO) and gender as moderators in the relationship between 1) exposure to community violence (ECV) and aggressive behavior and 2) coping and aggressive behavior

\begin{tabular}{|c|c|c|c|c|c|}
\hline & $\mathrm{b}$ & $\mathrm{SE}$ & $\beta$ & $t$ & $p$ \\
\hline Intercept & .80 & .05 & & 15.78 & $* * *$ \\
\hline Grade Level & -.04 & .02 & -.08 & -2.05 & $*$ \\
\hline Gender & .00 & .04 & .00 & .02 & \\
\hline $\mathrm{ECV}$ & .02 & .00 & .31 & 5.68 & $* * *$ \\
\hline Future orientation & -.10 & .09 & -.08 & -1.22 & \\
\hline Getting through & -.04 & .07 & -.05 & -.60 & \\
\hline Getting along & .08 & .06 & .11 & 1.39 & \\
\hline Getting away & .02 & .06 & .02 & .32 & \\
\hline $\mathrm{ECV} * \mathrm{FO}$ & .01 & .01 & .05 & .93 & \\
\hline ECV * Gender & .00 & .00 & .03 & .60 & \\
\hline $\mathrm{FO} *$ Gender & .00 & .12 & .00 & .03 & \\
\hline Getting through $* \mathrm{FO}$ & .27 & .20 & .12 & 1.35 & \\
\hline Getting along * FO & -.23 & .15 & -.12 & -1.50 & \\
\hline Getting away * FO & -.53 & .17 & -.24 & -3.09 & $* *$ \\
\hline Getting through $*$ Gender & .15 & .09 & .15 & 1.69 & \\
\hline Getting along * Gender & -.09 & .07 & -.09 & -1.21 & \\
\hline Getting away * Gender & -.15 & .08 & -.14 & -1.82 & \\
\hline Getting through * Getting along & -.12 & .06 & -.13 & -2.08 & $*$ \\
\hline Getting through * Getting away & -.08 & .07 & -.07 & -1.10 & \\
\hline Getting along * Getting away & .08 & .07 & .08 & 1.28 & \\
\hline $\mathrm{ECV} * \mathrm{FO} *$ Gender & .00 & .01 & -.01 & -.26 & \\
\hline Getting through $* \mathrm{FO} *$ Gender & -.05 & .26 & -.02 & -.20 & \\
\hline Getting along $* \mathrm{FO} *$ Gender & .08 & .20 & .03 & .42 & \\
\hline Getting away $* \mathrm{FO} *$ Gender & .50 & .22 & .17 & 2.23 & $*$ \\
\hline
\end{tabular}


Table 3.

Final model examining future orientation (FO) and gender as moderators in the relationship between 1) exposure to community violence (ECV) and delinquent behavior and 2) coping and delinquent behavior

\begin{tabular}{|c|c|c|c|c|c|}
\hline & $\mathrm{b}$ & SE & $\beta$ & $t$ & $p$ \\
\hline Intercept & .41 & .04 & & 10.13 & $* * *$ \\
\hline Grade Level & -.03 & .01 & -.07 & -1.87 & \\
\hline Gender & -.10 & .03 & -.12 & -3.16 & $* *$ \\
\hline $\mathrm{ECV}$ & .02 & .00 & .41 & 7.94 & $* * *$ \\
\hline Future orientation & -.29 & .07 & -.25 & -4.21 & $* * *$ \\
\hline Getting through & -.13 & .06 & -.19 & -2.35 & * \\
\hline Getting along & .04 & .04 & .06 & .81 & \\
\hline Getting away & .05 & .05 & .07 & 1.01 & \\
\hline $\mathrm{ECV} * \mathrm{FO}$ & -.01 & .01 & -.11 & -2.27 & $*$ \\
\hline ECV $*$ Gender & -.01 & .00 & -.11 & -1.97 & * \\
\hline $\mathrm{FO} *$ Gender & .04 & .09 & .02 & .40 & \\
\hline Getting through $*$ FO & .29 & .16 & .15 & 1.79 & \\
\hline Getting along $*$ FO & -.07 & .12 & -.04 & -.56 & \\
\hline Getting away $*$ FO & -.47 & .14 & -.25 & -3.46 & $* *$ \\
\hline Getting through $*$ Gender & .20 & .07 & .23 & 2.84 & ** \\
\hline Getting along * Gender & -.06 & .06 & -.08 & -1.06 & \\
\hline Getting away * Gender & -.15 & .07 & -.16 & -2.29 & * \\
\hline Getting through $*$ Getting along & -.06 & .05 & -.07 & -1.21 & \\
\hline Getting through $*$ Getting away & -.06 & .06 & -.07 & -1.14 & \\
\hline Getting along * Getting away & .06 & .05 & .08 & 1.23 & \\
\hline $\mathrm{ECV} * \mathrm{FO} *$ Gender & .01 & .01 & .03 & .57 & \\
\hline Getting through $* \mathrm{FO} *$ Gender & -.27 & .21 & -.10 & -1.29 & \\
\hline Getting along * FO * Gender & .09 & .16 & .04 & .57 & \\
\hline Getting away $* \mathrm{FO} *$ Gender & .45 & .18 & .19 & 2.53 & $*$ \\
\hline
\end{tabular}

Notes: Predictor variables are centered; ECV $=$ Exposure to community violence; $F O=$ future orientation; *** $p$

$<.001,{ }^{* *} p<.01, * p<.05$ 
Figure 1. Simple slope analyses depicting the relationship between exposure to community violence (ECV) and delinquent behaviors at high and low levels of future orientation (FO)

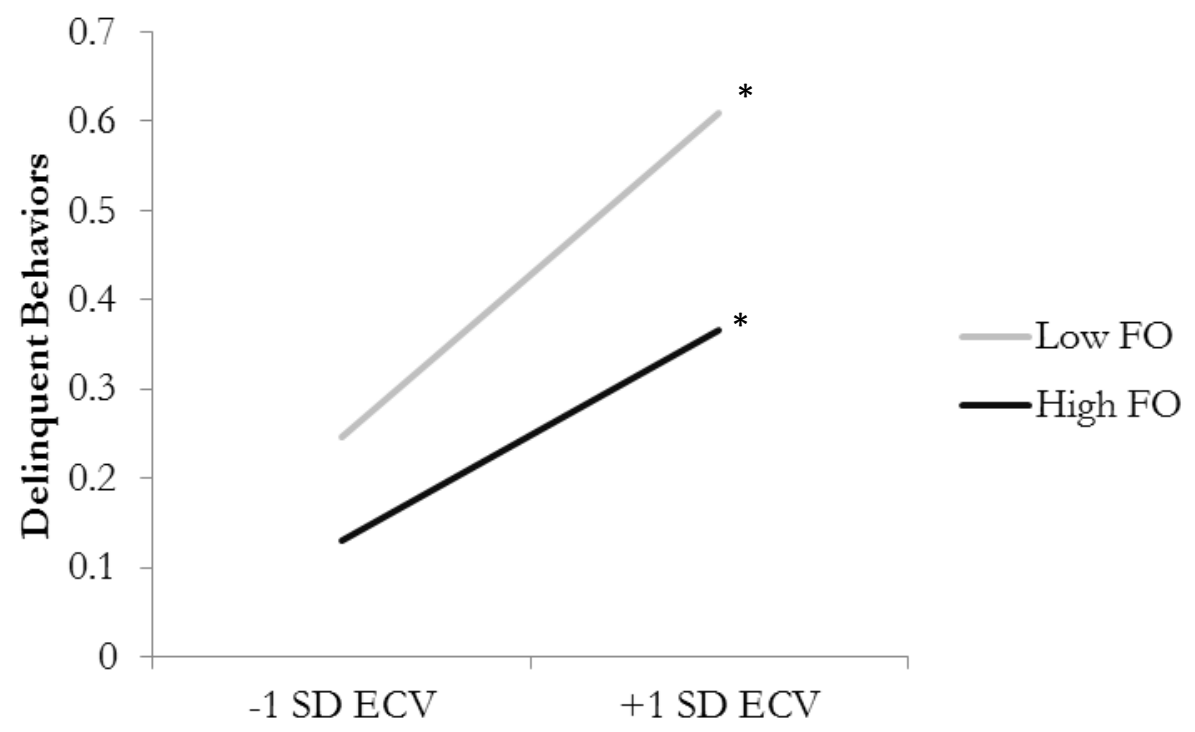

